\title{
Optimal Conditions for Sampling Reference Ranges of Blood Cytokine Tests Using AimPlex Flow Cytometry
}

\author{
Kaiwen Wang, Haiting Yang, Jiaxian Huang, Xiaoxiang Chen and Jiangfeng Zhao* \\ Department of Rheumatology, Ren Ji Hospital, School of Medicine, Shanghai Jiaotong University, Shanghai, P.R. China \\ *Corresponding author: Jiangfeng Zhao, Renji Hospital, Shanghai Jiao Tong University School of Medicine, Shanghai, P.R. \\ China
}

\begin{abstract}
ARTICLE INFO
Received: August 28, 2021

Published: September 13, 2021

Citation: Kaiwen Wang, Haiting Yang, Jiaxian Huang, Xiaoxiang Chen, Jiangfeng Zhao. Optimal Conditions for Sampling Reference Ranges of Blood Cytokine Tests Using AimPlex Flow Cytometry. Biomed J Sci \& Tech Res 38(4)-2021. BJSTR. MS.ID.006193.
\end{abstract}

Keywords: Cytokines; AimPlex; Flow Cytometry Immunoassay

\section{ABSTRACT}

Objectives: Cytokine research is of great theoretical and practical significance; it can help to elucidate the mechanism of immune regulation at the molecular level, thereby aiding diagnosis, prevention, and treatment of diseases. Here, we aimed to clarify the effect of detection method, pre-treatment, and storage conditions of specimens on the accurate assessment of cytokine levels in vivo.

Methods: We selected four kinds of vacuum blood collection tubes, containing EDTA, heparin, clot activator, and gel, separately, and compared the changes in expression of 14 cytokines in serum and plasma samples, at different temperatures and durations of storage, using AimPlex flow cytometry-based immunoassay.

Results: The cytokine levels were significantly higher in plasma than in serum from normal individuals. Reliable values for most cytokines were obtained in gel-serum samples, centrifuged within $4 \mathrm{~h}$ of collection and stored at $-20^{\circ} \mathrm{C}$ for up to $24 \mathrm{~h}$, in both normal population and patients with connective tissue disease. IL-6 and IL-8 levels were significantly increased, to different extents, after being preserved under various conditions; the increase was minimal and closest to the value of fresh blood when stored up to $24 \mathrm{~h}$ at $-20^{\circ} \mathrm{C}$ in the gel-serum.

Conclusion: Cytokines are more stable in gel-serum than in plasma or clot activatorserum, as estimated by AimPlex flow cytometry-based immunoassay. The best time for testing would be within $4 \mathrm{~h}$ (immediately) or within $24 \mathrm{~h}$ if centrifuged and stored at $-20^{\circ} \mathrm{C}$ in CTD patients.

\section{Introduction}

Cytokines are small molecular peptides or glycoproteins, synthesized and secreted mainly by immune cells. They play a variety of biological functions in inflammatory diseases by mediating interactions across cells [1]. Release of cytokines leads to the activation of immune cells and production of more cytokines, a process referred to as "cytokine storm" [2]. Variation in the levels of cytokines can provide valuable information regarding the diagnosis and prognosis of autoimmune diseases [3,4]. A number of stimuli, including $\mathrm{C} 5 \mathrm{a}$, IgA-type immune complexes, and bacterial products, may stimulate cytokine synthesis [5-7]. In addition, cytokine levels may be altered due to blood collection techniques and storage conditions of the blood samples [8-10]. As per the recommended methods, serum has been used for a long time for cytokine measurements by ELISA. However, when the blood is collected into tubes, owing to the bio-incompatibility between blood cells and tube walls, coagulation gets activated and thrombin activates protease receptors, leading to the release of IL-1 $\beta$, IL-6, IL-10, and TNF- $\alpha$ [11-13].

Some studies have also confirmed anticoagulants, such as EDTA, to inhibit the complement system activation for use in cytokine analyses [14]. According to Linda Torrissen Hennø, et al., EDTA-plasma is the best choice for cytokine detection using a Bio- 
Plex Pro Human Cytokine 27-Plex Panel kit [15]. Compared to the traditional single cytokine detection method (such as ELISA), the multiplex flow immunoassay developed here focused on plasma and/or serum samples and the pre-analytical sampling conditions. To obtain cytokine values representative of the conditions in vivo, EDTA-and heparin (anticoagulant)-plasma, and clot activatorand gel-sera were collected from twelve healthy blood donors and ten patients with connective tissue diseases. The levels of 14 cytokines were examined using flow cytometry-based multiplex immunoassay; the influence of storage time and temperature were also investigated.

\section{Materials and Methods}

\section{Population}

Twelve healthy blood donors (five females and seven males, age range 22-63 years) and ten donors with connective tissue disease (five females and five males, age range 22-70 years; SLE $(n=4)$, dermatomyositis ( $\mathrm{n}=2)$, vasculitis $(\mathrm{n}=2)$, Connective tissue diseases $(\mathrm{n}=1)$, and IgG4-related disease $(\mathrm{n}=1)$ ) were enrolled in the study. The healthy donors did not have any medication, fever, infection, or inflammatory disease within a month prior to blood sampling. All participants signed the informed consent form. The study was approved by the ethics committee of Ren Ji Hospital (ShangHai, China).

\section{Sample Collection and Storage Conditions}

Blood for serum samples was collected in tubes containing clot activator (GongDong medical instrument co., LTD, China) and gel (BD Vacutainer ${ }^{\circ}$, USA). Blood for plasma was collected in tubes containing EDTA (GongDong medical instrument co., LTD, China) and heparin (GongDong medical instrument co., LTD, China). All tubes were gently rotated ten times by hand, after sampling, followed by centrifugation at $4000 \times \mathrm{g}$ for $10 \mathrm{~min}$ at RT. Plasma or serum, isolated from each tube, was divided into five parts, marked as $4 \mathrm{~h}, 1$ day, 3 days, 5 days, and 7 days, respectively. The 1-day specimen was further divided into three parts, and stored at $4^{\circ} \mathrm{C}$, $-20^{\circ} \mathrm{C}$, and $-80^{\circ} \mathrm{C}$.

\section{Cytokine Analyses}

Cytokines in the plasma and serum samples were tested using an AimPlex Human Cytokine 14-Plex Panel kit (Tianjin Kuang Bo Tongsheng Biotechnology Co., Ltd, China). The specific cytokines, namely IL-1 $\beta$ (cut-off value $\leq 3.40 \mathrm{pg} / \mathrm{mL}$, IL-2 (cut-off value $\leq 6.64$ $\mathrm{pg} / / \mathrm{mL}$ ), IL-4 (cut-off value $\leq 4.19 \mathrm{pg} / \mathrm{mL}$ ), IL-5 (cut-off value $\leq$ $4.15 \mathrm{pg} / \mathrm{mL}$ ), IL-6 (cut-off value $\leq 11.09 \mathrm{pg} / \mathrm{mL}$ ), IL-8 (cut-off value $\leq 15.71 \mathrm{pg} / \mathrm{mL}$ ), IL-10 (cut-off value $\leq 4.50 \mathrm{pg} / \mathrm{mL}$ ), IL-12p70 (cutoff value $\leq 10.18 \mathrm{pg} / \mathrm{mL}$ ), IL-17A (cut-off value $\leq 4.74 \mathrm{pg} / \mathrm{mL}$ ), IL$17 \mathrm{~F}$ (cut-off value $\leq 4.66 \mathrm{pg} / \mathrm{mL}$ ), IL-22 (cut-off value $\leq 3.64 \mathrm{pg}$ / $\mathrm{mL}$ ), IFN- $\gamma$ (cut-off value $\leq 4.43 \mathrm{pg} / \mathrm{mL}$ ), TNF- $\alpha$ (cut-off value $\leq$ $4.50 \mathrm{pg} / \mathrm{mL}$ ), and TNF- $\beta$ (cut-off value $\leq 2.54 \mathrm{pg} / \mathrm{mL}$ ) were analyzed using the CellQuest analysis platform (BD FACS Calibur, USA). The analyses were performed according to the manufacturer's instructions.

\section{Statistical Analyses}

SPSS 23.0 (Statistical Product and Service Solutions Software, US) and GraphPad Prism 6.0 (GraphPad Software, CA) were used for the statistical calculations and figures. Multiple independent samples were analyzed by Kruskal-Wallis test and Mann-Whitney $\mathrm{U}$ test. Wilcoxon test was used to compare the difference between the levels of cytokines under different conditions and the initial value within $4 \mathrm{~h}$. Data regarding storage of serum and plasma at different temperatures $\left(4^{\circ} \mathrm{C},-20^{\circ} \mathrm{C}\right.$, and $\left.-80^{\circ} \mathrm{C}\right)$ were analyzed separately, time being the only variable, by comparing samples at other temperatures with those processed immediately within $4 \mathrm{~h}$ in the same series. $\mathrm{P}<0.05$ was considered to imply significant differences.

\section{Results}

\section{Analysis of Cytokine Levels in Plasma and Serum Samples Collected from Normal Subjects and Centrifuged Immediately}

Fourteen cytokines were detected in twelve normal human samples collected from four types of blood vessels (EDTA, heparin, clot activator, and gel) within $4 \mathrm{~h}$ of blood sampling (Table 1 ). Results showed the levels of IL-2, IL-17F, and IL-22 in plasma to be significantly higher than those in serum $(\mathrm{P}<0.05)$. The level of IL-4 detected in EDTA-plasma was higher than in clot activator-serum. Compared to that in heparin-plasma, the levels of IL-5, IL-8, and IL-17A in the two serum tubes were significantly lower $(\mathrm{P}<0.05)$. TNF- $\beta$ level in EDTA-plasma was significantly higher than in the two kinds of sera $(\mathrm{P}<0.05)$. There was no difference in other cytokines between the serum and plasma samples. Despite some differences in the serum and plasma samples, results of all cytokines were within the cut-off value set by the manufacturer (Figure 1).

Table 1: Reference ranges of cytokines in plasma and serum from healthy individuals.

\begin{tabular}{|c|c|c|c|c|c|c|c|c|}
\hline & \multicolumn{2}{|c|}{ EDTA } & \multicolumn{2}{c|}{ Heparin } & \multicolumn{2}{c|}{ Clot Activator } \\
\hline Cytokines & Median & $\mathbf{9 5}^{\text {th }}$ Percentiles & Median & 95 $^{\text {th }}$ Percentiles & Median & 95 $^{\text {th }}$ Percentiles & Median $^{\mathbf{9 5}^{\text {th }}}$ Percentiles \\
\hline IL-1 $\beta$ & 0.00 & $0.00-0.00$ & 0.00 & $0.00-0.35$ & 0.00 & $0.00-0.00$ & 0.00 & $0.00-0.00$ \\
\hline IL-2 & 1.44 & $0.80-1.76$ & 1.61 & $0.65-1.97$ & 0.62 & $0.10-0.88$ & 0.57 & $0.37-1.07$ \\
\hline IL-4 & 0.00 & $0.00-0.00$ & 0.07 & $0.00-0.98$ & 0.00 & $0.00-0.00$ & 0.00 \\
\hline
\end{tabular}




\begin{tabular}{|c|c|c|c|c|c|c|c|c|}
\hline IL-5 & 0.57 & $0.35-1.29$ & 1.25 & $0.77-1.67$ & 0.34 & $0.17-0.53$ & 0.23 & $0.01-0.46$ \\
\hline IL-6 & 1.85 & $1.12-2.82$ & 3.41 & $1.45-5.31$ & 1.35 & $0.88-2.67$ & 1.59 & $0.84-3.34$ \\
\hline IL-8 & 7.63 & $6.96-9.35$ & 8.97 & $7.70-14.14$ & 3.85 & $2.81-5.97$ & 3.38 & $2.34-6.77$ \\
\hline IL-10 & 0.00 & $0.00-0.00$ & 0.00 & $0.00-0.00$ & 0.00 & $0.00-0.00$ & 0.00 & $0.00-0.00$ \\
\hline IL-12p70 & 1.34 & $1.23-1.53$ & 1.39 & $1.30-1.57$ & 1.25 & $1.12-1.36$ & 1.30 & $1.14-1.48$ \\
\hline IL-17A & 1.10 & $0.47-1.77$ & 1.27 & $0.67-2.01$ & 0.50 & $0.26-0.77$ & 0.59 & $0.09-0.74$ \\
\hline IL-17F & 2.27 & $2.17-2.37$ & 2.53 & $2.12-2.77$ & 1.82 & $1.58-1.94$ & 1.77 & $1.58-2.12$ \\
\hline IL-22 & 0.08 & $0.00-0.80$ & 0.14 & $0.03-0.68$ & 0.00 & $0.00-0.00$ & 0.00 & $0.00-0.00$ \\
\hline TNF- $\alpha$ & 0.07 & $0.00-0.28$ & 0.00 & $0.00-0.51$ & 0.00 & $0.00-0.00$ & 0.00 & $0.00-0.05$ \\
\hline TNF- $\beta$ & 1.69 & $0.84-2.49$ & 0.55 & $0.18-1.69$ & 0.32 & $0.00-0.46$ & 0.19 & $0.00-0.58$ \\
\hline IFN- $\gamma$ & 0.61 & $0.23-0.73$ & 1.28 & $0.59-2.15$ & 0.77 & $0.45-1.10$ & 0.61 & $0.38-0.87$ \\
\hline
\end{tabular}

Note: IL: interleukin; TNF: Tumour Necrosis Factor; IFN: Interferon. All cytokines are expressed as pg/mL.

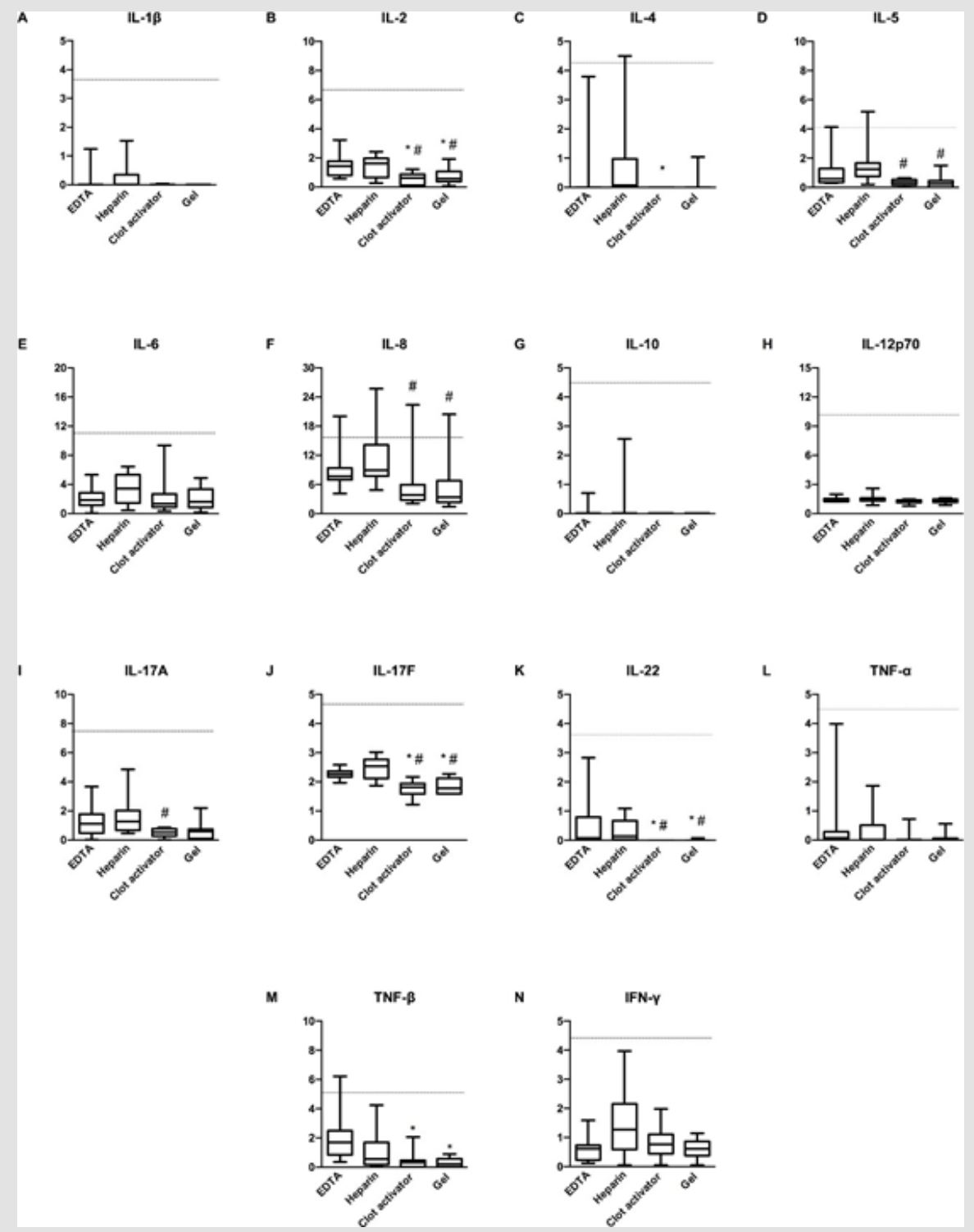

Figure 1: Cytokine levels in serum and plasma samples compared to the cut-off value set by the manufacturers. The levels of (A) IL-1 $\beta$, (B) IL-2, (C) IL-4, (D) IL-5, (E) IL-6, (F) IL-8, (G) IL-10, (H) IL-12p70, (I) IL-17A, (J) IL-17F, (K) IL-22, (L) TNF-a, (M) TNF- $\beta$, and (N) IFN- $\gamma$ were analyzed using AimPlex technology and expressed as $\mathrm{pg} / \mathrm{mL}$ on the $\mathrm{Y}$ axis. Data are presented as median values with whiskers $\left(10^{\text {th }}\right.$ and $90^{\text {th }}$ percentiles, $\left.\mathrm{n}=12\right)$. ${ }^{*} \mathrm{P}<0.05$ compared to that detected in the EDTA tube. \#P<0.05 compared to that detected in the heparin tube. 
Effect of Storage Temperature and Time on Cytokine Levels in a Normal Person

A

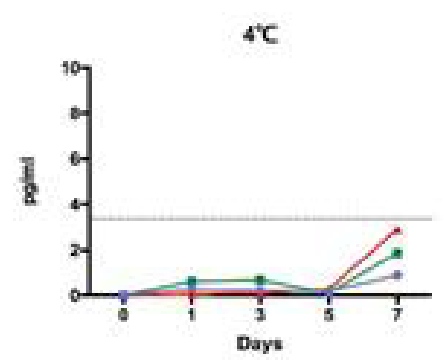

B

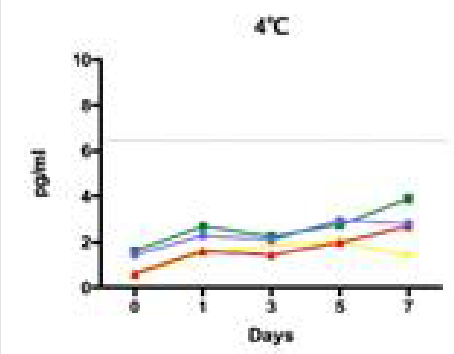

C

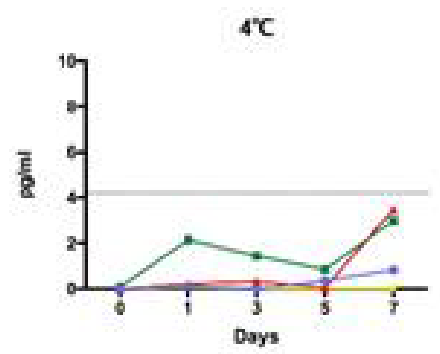

D

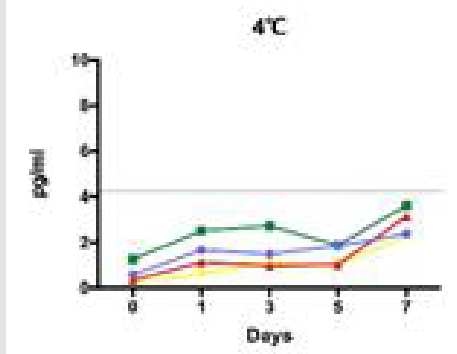

E

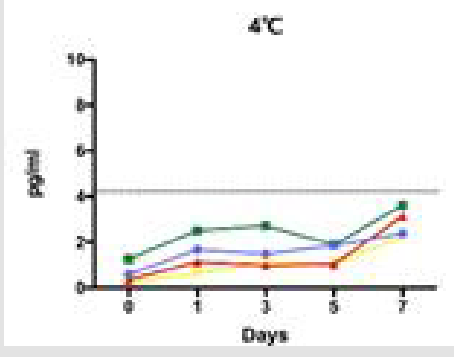

\section{IL-1 $\beta$}

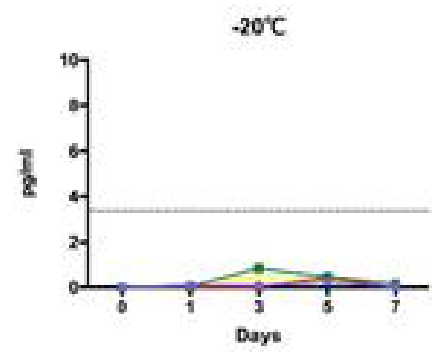

IL-2

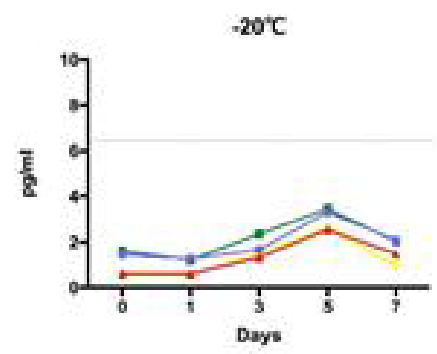

$\mathrm{IL}-4$

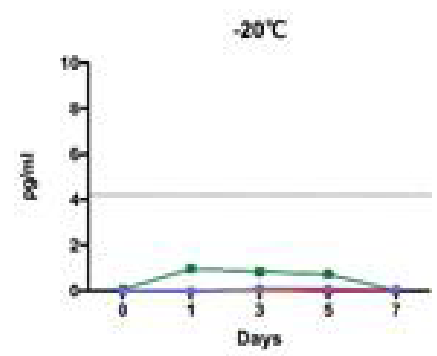

IL-5

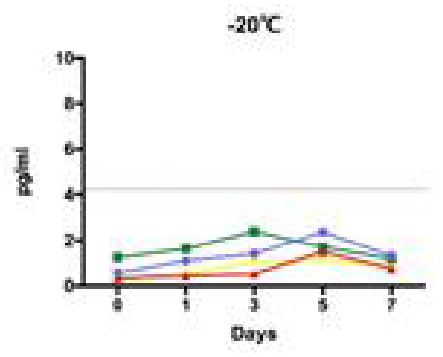

IL-6

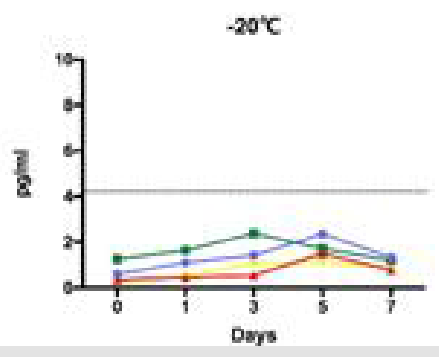

$-80^{\circ} \mathrm{C}$

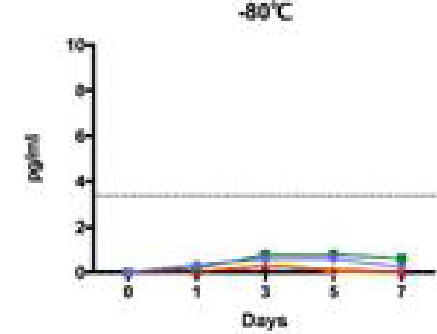

$-80^{\circ} \mathrm{C}$

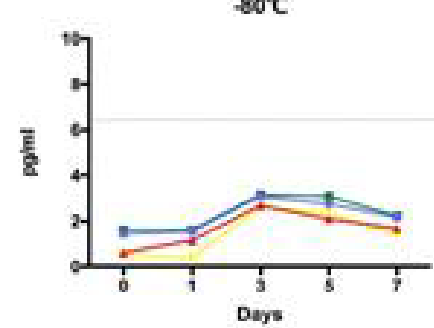

$-80^{\circ} \mathrm{C}$

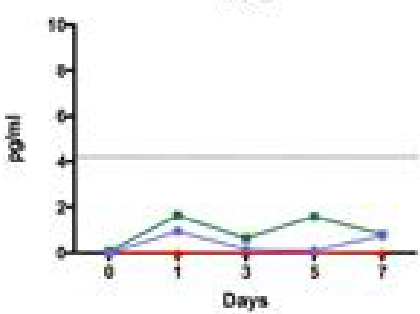

$-80^{\circ} \mathrm{C}$

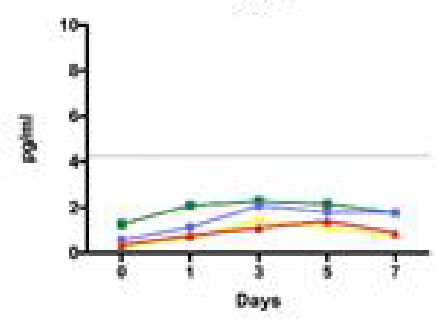

$-80^{\circ} \mathrm{C}$

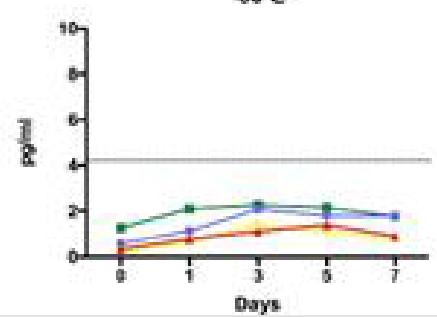




型




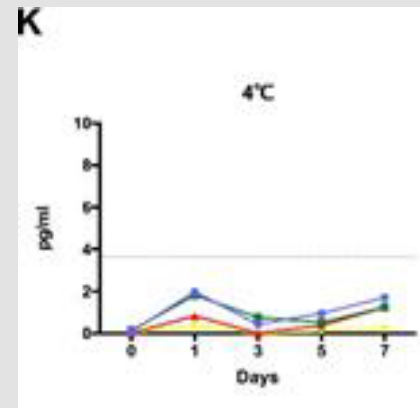

L

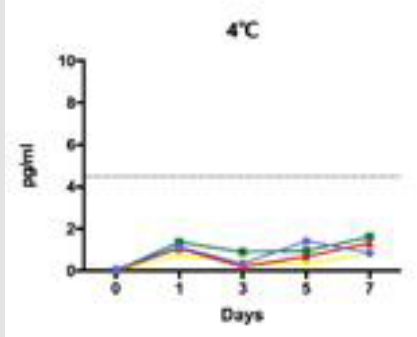

M

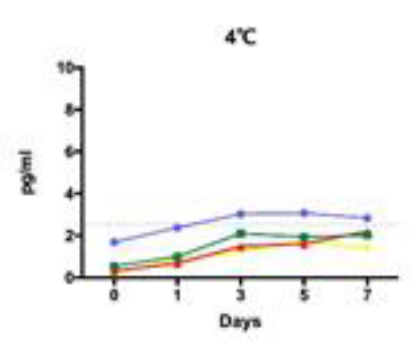

N

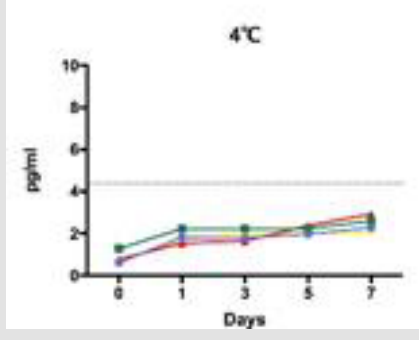

IL-22

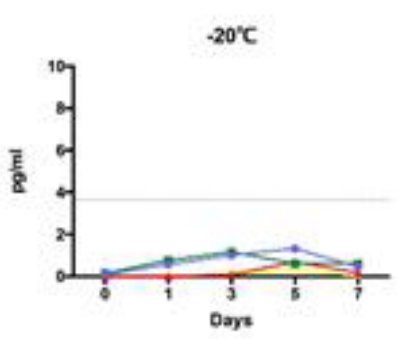

TNF- $a$

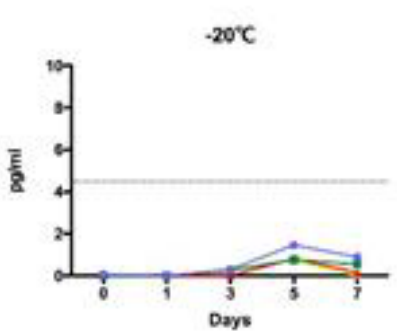

TNF- $\beta$

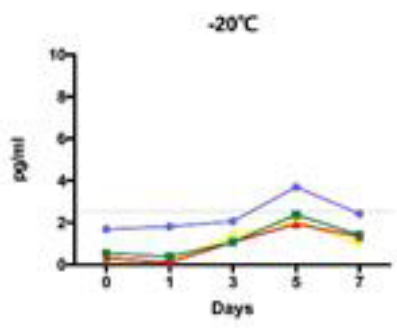

IFN-y

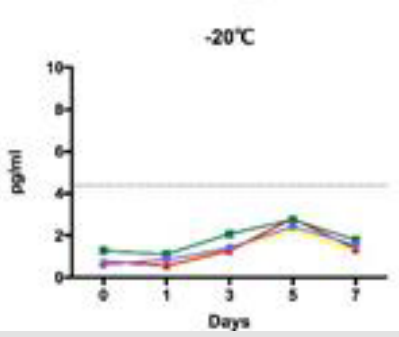

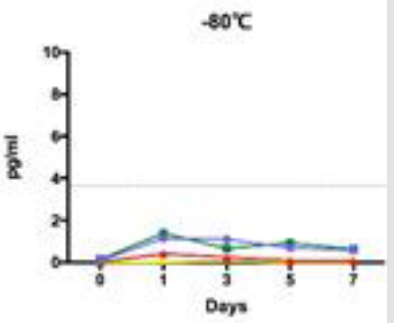

$-80^{\circ} \mathrm{C}$

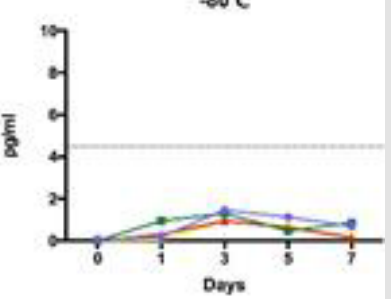

$-80 \mathrm{C}$

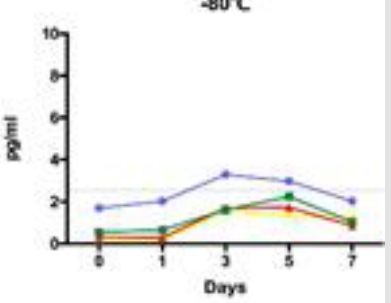

$-80^{\circ} \mathrm{C}$

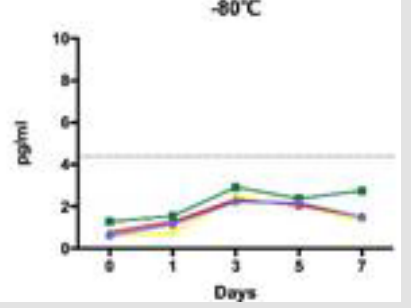

Figure 2: Cytokine levels in clot activator- and gel-serum samples from normal individuals. The levels of fourteen cytokines were analyzed using AimPlex technology and expressed as pg/mL. The detected values in four tubes were compared with the cut-off value. Purple: EDTA-plasma tube, green: heparin-plasma tube, red: clot activator-serum tube, yellow: gel-serum tube.

We studied the changes in 14 cytokines, after storage for 1 day, 3 days, 5 days, and 7 days at $4{ }^{\circ} \mathrm{C},-20^{\circ} \mathrm{C}$, and $-80^{\circ} \mathrm{C}$. Results showed most cytokine levels to not exceed the cut-off value, under any storage condition, except for IL-8 and TNF- $\beta$. When IL-8 was stored at $4^{\circ} \mathrm{C}$ for 1 day, its level in plasma samples exceeded the cut-off value; that in clot activator-serum exceeded the cut-off value after 5 days. Under the storage conditions of $-20^{\circ} \mathrm{C}$ and $-80^{\circ} \mathrm{C}$, the detection levels in both kinds of plasma and clot activator-serum were close to or more than the cut-off values after 1 day. The level of IL-8, however, was always below the cut-off value at these storage temperatures and time in the gel-serum sample. For TNF- $\beta$, the detection value in EDTA-plasma was close to or more than the cut-off value after1-day storage at $4^{\circ} \mathrm{C}$, whereas it exceeded the cut-off value after 3 days at $-20^{\circ} \mathrm{C}$ and $-80^{\circ} \mathrm{C}$ (Figure 2). In the normal population, levels of IL-8 and TNF- $\beta$ detected in plasma were significantly higher than those detected in serum within $4 \mathrm{~h}$, and the levels in plasma samples under different storage conditions increased and even exceeded the cut-off value (Figure 1). Collectively, the results showed that plasma samples may not be suitable for this cytokine detection method. 


\section{Validation of Cytokine Levels in Connective Tissue Disease Using Serum and Plasma Samples}

Based on the results from normal samples, we expected no difference in the levels of cytokines across the four kinds of vacuum blood collection systems within $4 \mathrm{~h}$ in CTD samples. Samples from ten patients with CTD were tested within $4 \mathrm{~h}$, after centrifugation, and results were consistent with those in normal samples. Most of the factors had no difference in the detected values across the four tubes. Expression of IL-5, IL-8, and IL-17F in heparin-plasma was significantly higher than in gel-serum. We, therefore, believed that heparin-plasma may not be the most suitable sample for patients with CTD (Figure 3).
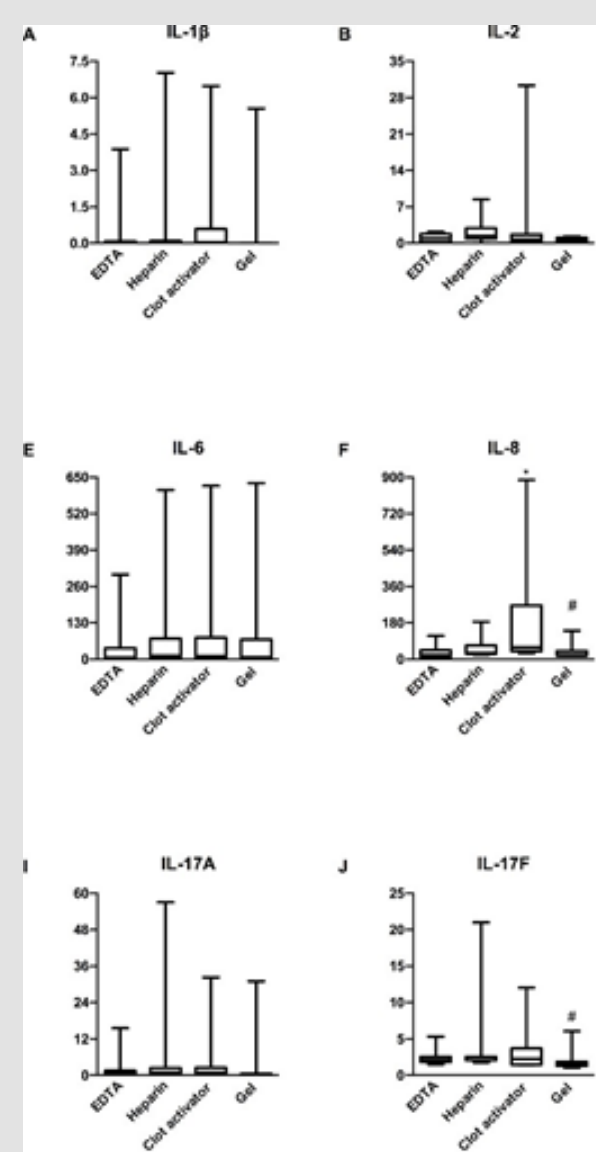

\section{c}

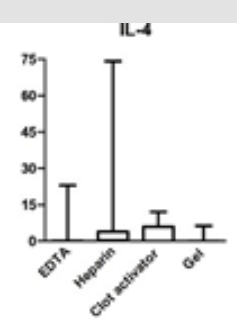

6

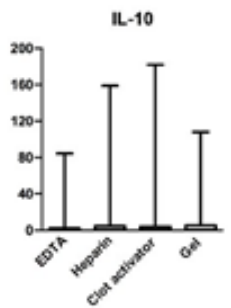

$\kappa$
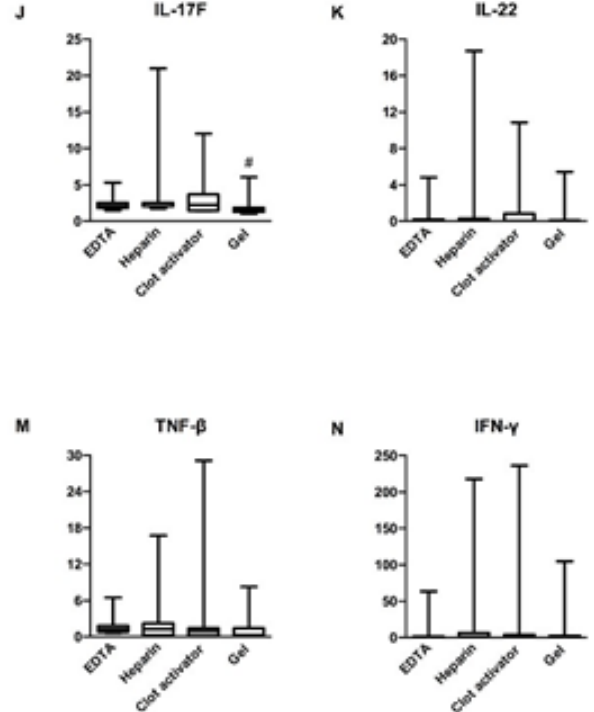

D

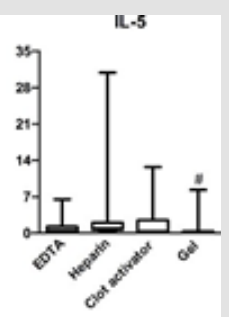

H
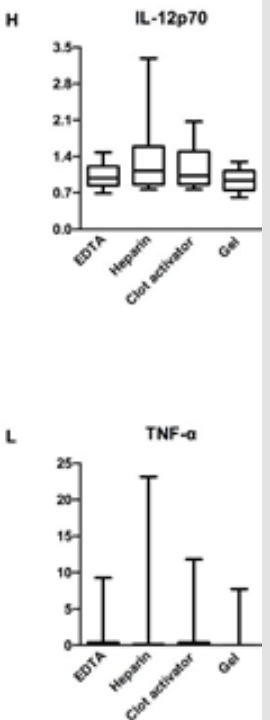

Figure 3: Cytokine levels in serum samples compared to that in plasma samples from patients with connective tissue disease. The levels of (A) IL-1 $\beta$, (B) IL-2, (C) IL-4, (D) IL-5, (E) IL-6, (F) IL-8, (G) IL-10, (H) IL-12p70, (I) IL-17A, (J) IL-17F, (K) IL-22, (L) TNF- $\alpha,(M)$ TNF- $\beta$, and (N) IFN- $\gamma$ were analyzed using AimPlex technology and expressed as pg/mL on the $Y$ axis. The data are given as median values with whiskers $\left(10^{\text {th }}\right.$ and $90^{\text {th }}$ percentiles, $\left.n=12\right)$. ${ }^{*} \mathrm{P}<0.05$ compared to that detected in the EDTA tube. \#P $<0.05$ compared to that detected in the heparin tube. 
Effect of Storage Temperature and Time on Cytokine Levels in Patients with CTD

A

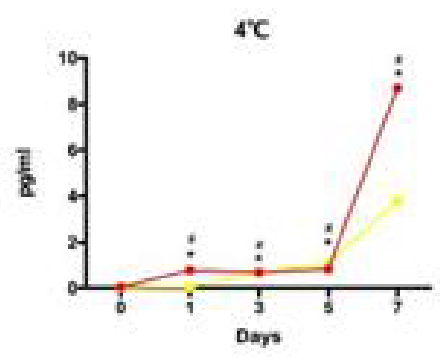

B

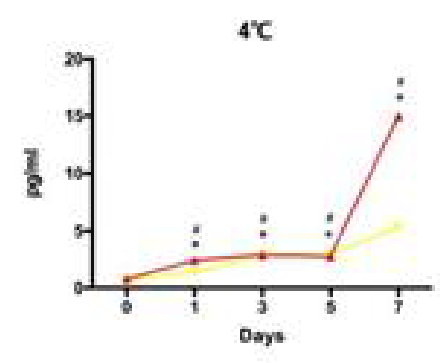

C

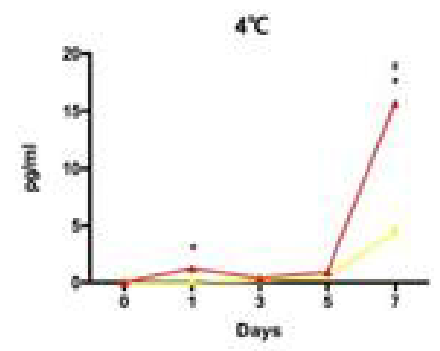

D

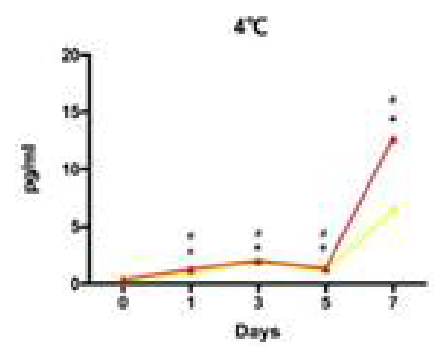

E

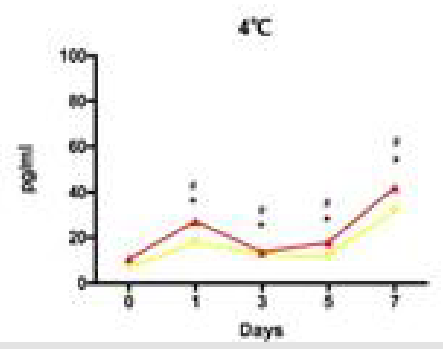

IL-1 $\beta$

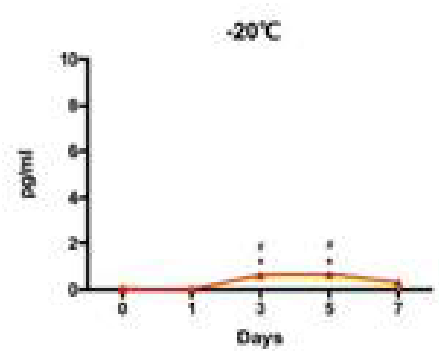

IL-2

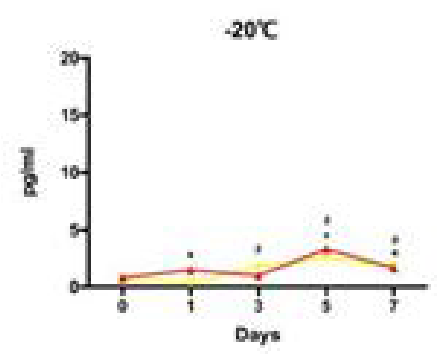

IL-4

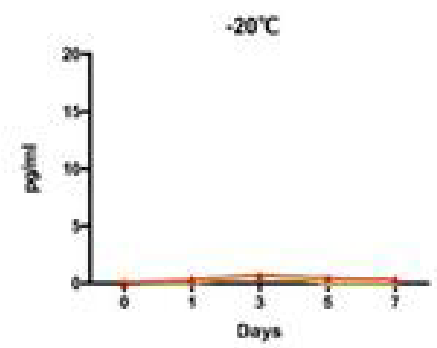

IL-5

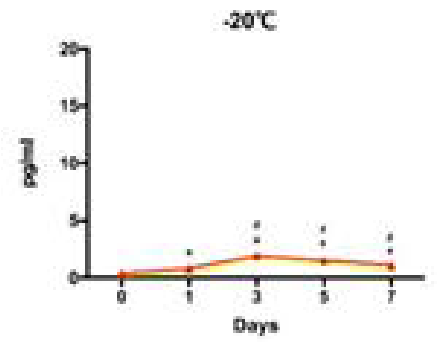

IL-6

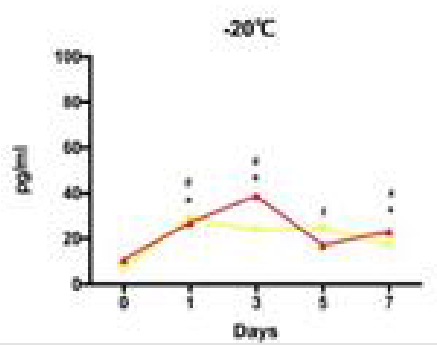

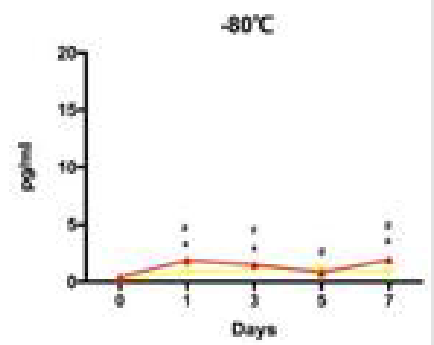
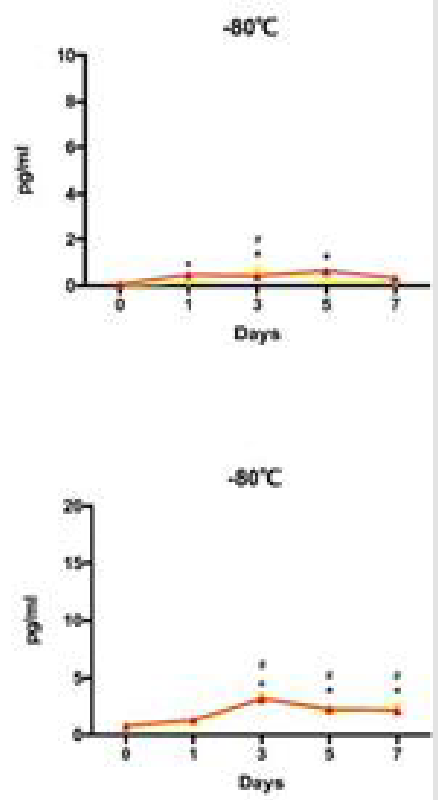

$-80^{\circ} \mathrm{C}$
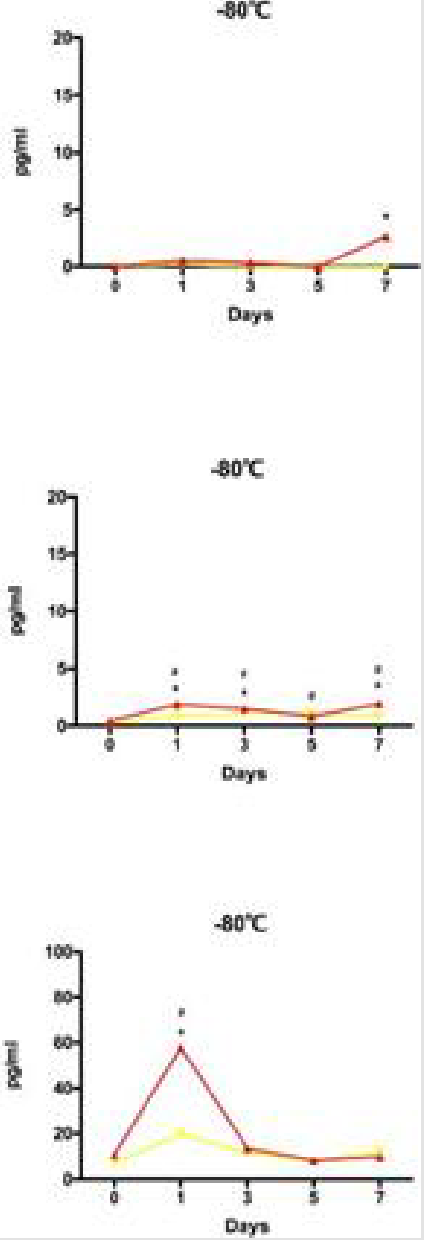
$\mathbf{F}$

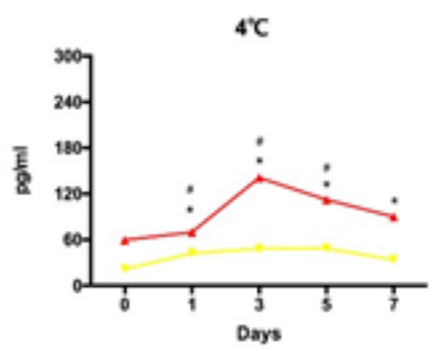

G

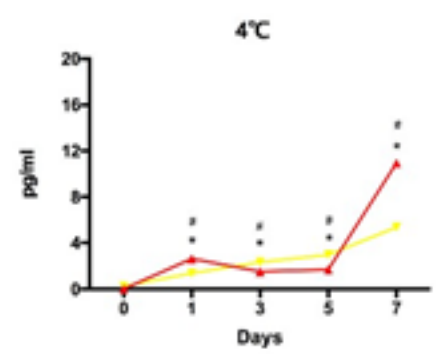

H

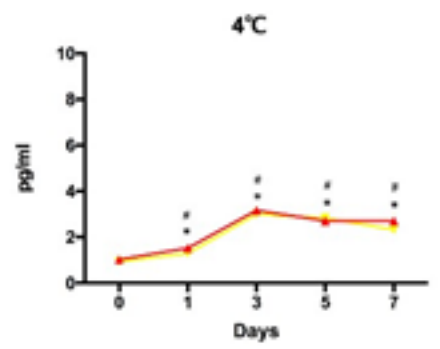

I

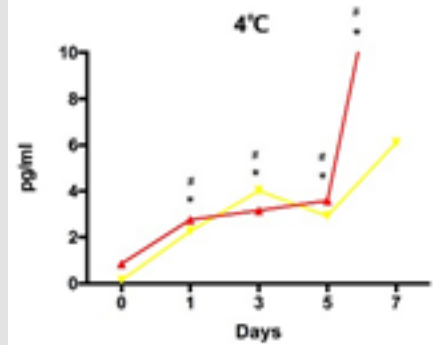

$\mathbf{J}$

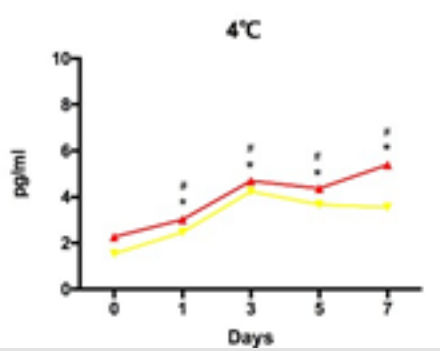

IL-8

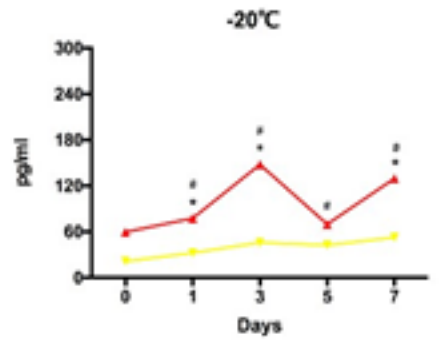

IL-10

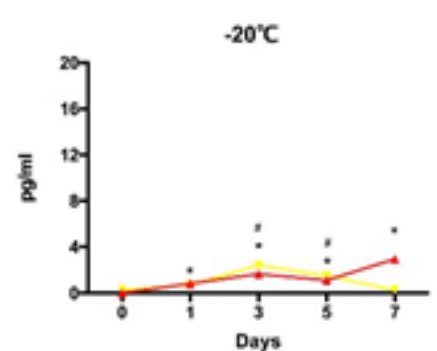

IL-12p70

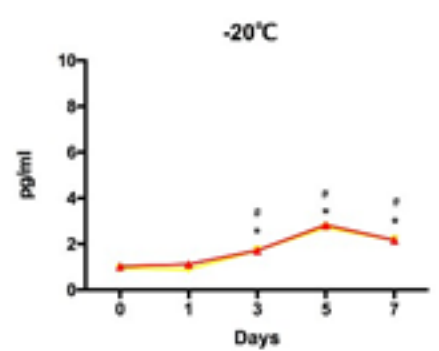

IL-17A
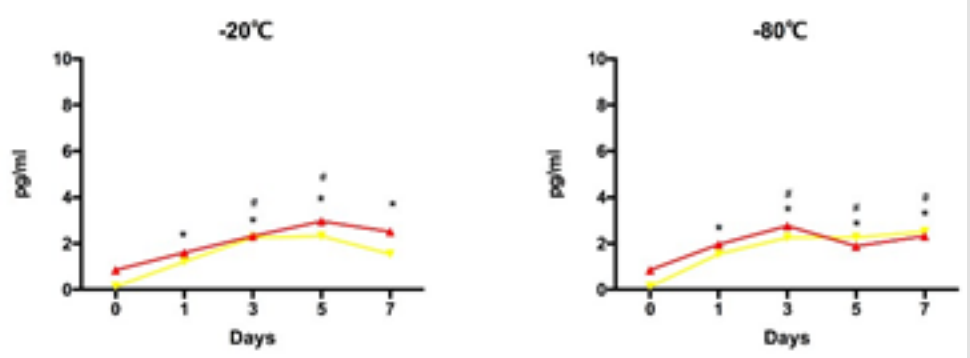

IL-17F

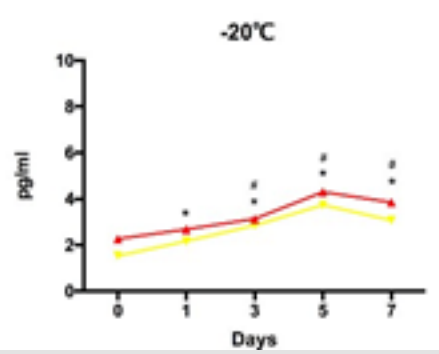

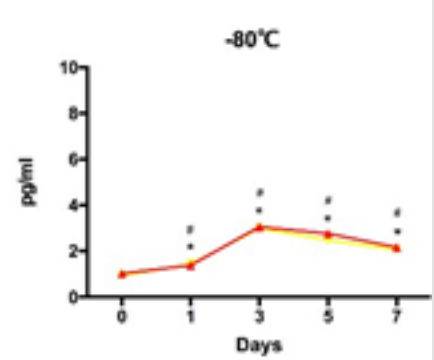

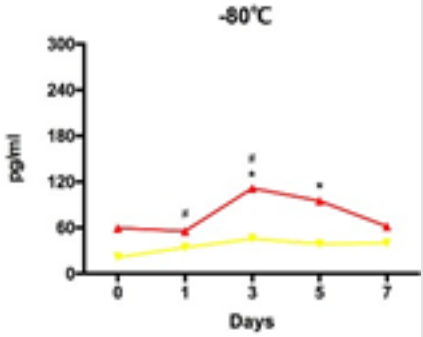

$-80^{\circ} \mathrm{C}$
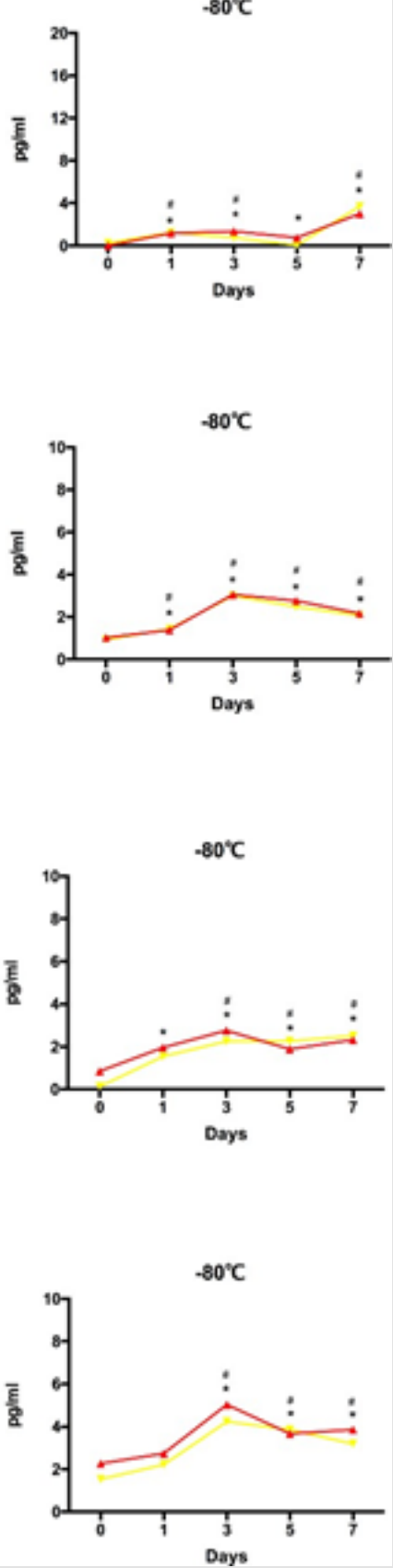


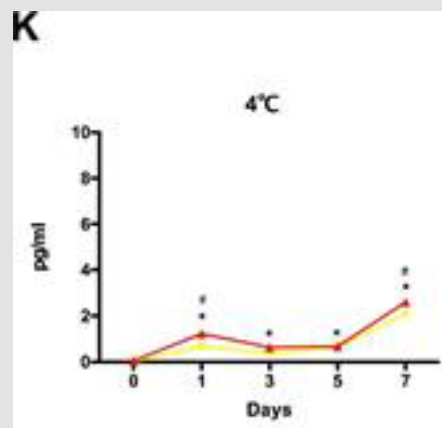

L

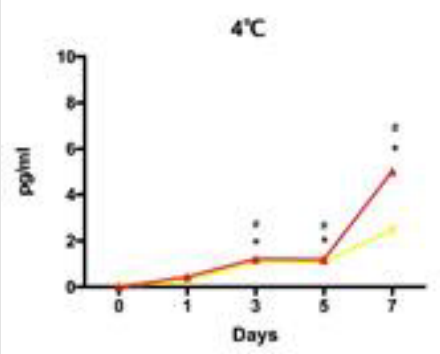

M

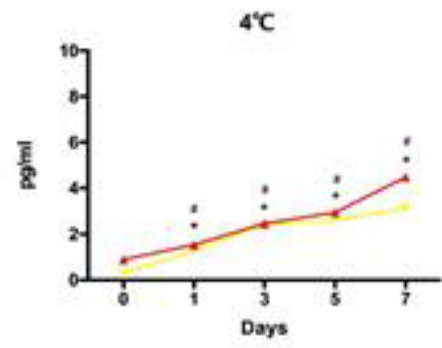

N

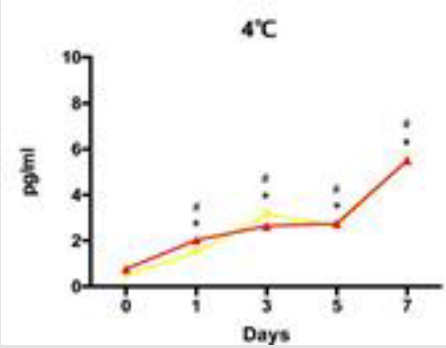

IL-22

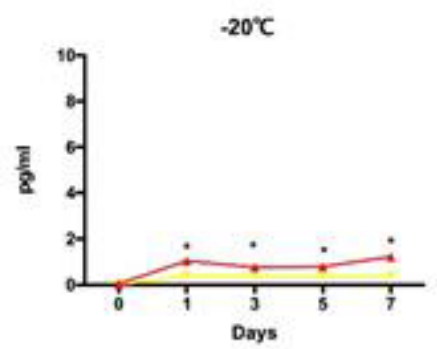

TNF- $\alpha$

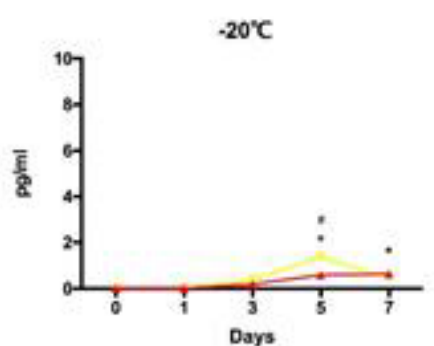

TNF- $\beta$

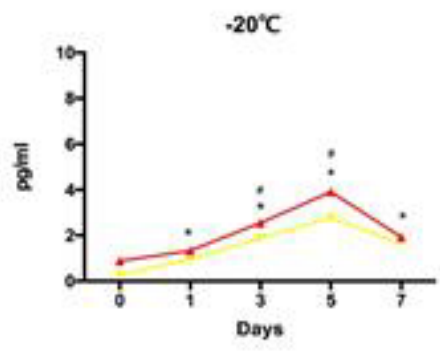

IFN-Y

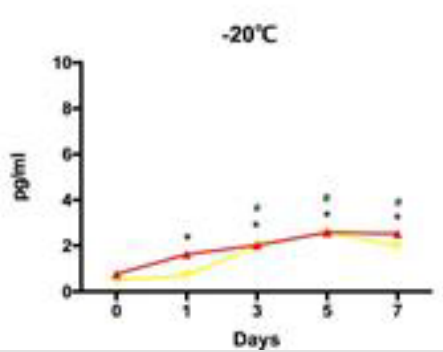

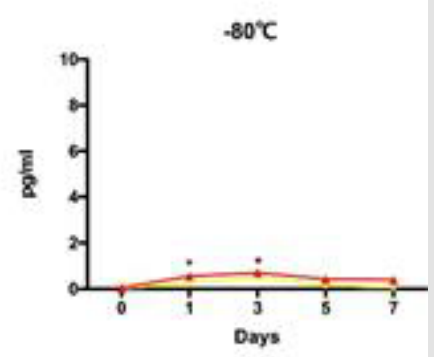

$-80^{\circ} \mathrm{C}$
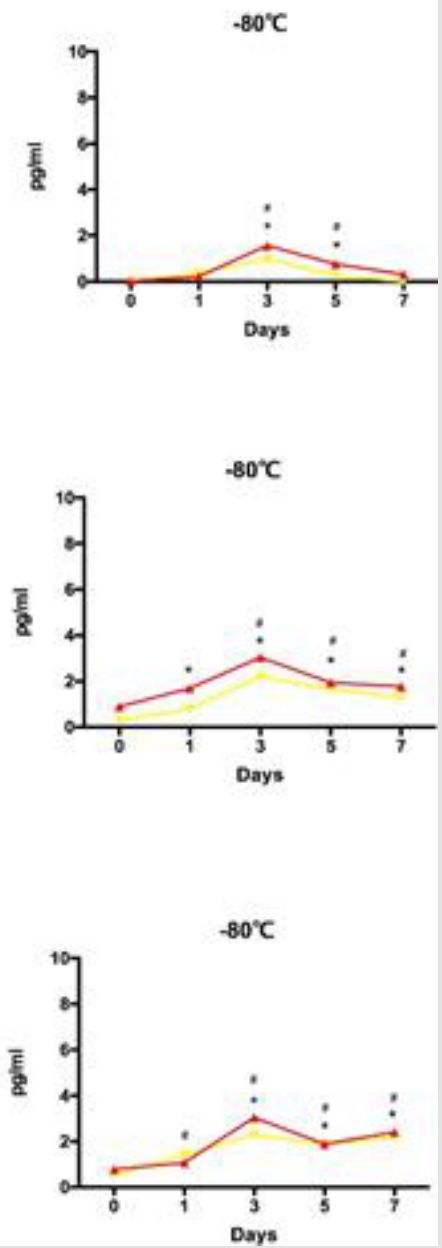

Figure 4: Cytokine levels in clot activator- and gel-serum samples from patients with CTD. The levels of fourteen cytokines were analyzed using AimPlex technology and expressed as $\mathrm{pg} / \mathrm{mL} .{ }^{*} \mathrm{P}<0.05$ compared to the day- 0 value detected in the in clot activator-tube. \#P $<0.05$ compared to the day- 0 value detected in the gel tube. Red: clot activator-serum tube, yellow: gelserum tube.

In order to study the 14 cytokines better and understand the storage conditions at which they are most stable, we investigated their changes in the serum and plasma (from 10 patients with CTD) samples stored at $4{ }^{\circ} \mathrm{C},-20^{\circ} \mathrm{C}$, and $-80^{\circ} \mathrm{C}$ for 1 day, 3 days, 5 days, and 7 days. Results showed most of the cytokines to be detectable in 1 day, 3 days, 5 days, and 7 days, when preserved at $4^{\circ} \mathrm{C}$; they were increased in both serum and plasma with statistically significant differences (Data not shown). We compared the two types of serum, and found that, on the first day of storage at $-20^{\circ} \mathrm{C}$, except for IL-6 and IL-8, there was no difference in the detection value in gel-serum compared to that detected within $4 \mathrm{~h}$. However, the detection value of clot activator-serum after 1-day storage was different from that within $4 \mathrm{~h}$ for most cytokines. Under the storage condition of $-80^{\circ} \mathrm{C}$, the cytokine levels detected were obviously different within 1 day 
of storage, compared to that at $4^{\circ} \mathrm{C}$. Therefore, for patients with CTD, gel-serum stored at $-20^{\circ} \mathrm{C}$ up to 1 day would be most suitable for the combined detection of 14-plex cytokines (Figure 4).

\section{Discussion}

Our study collectively indicated that blood sampling conditions, especially storage temperature and time, greatly affect the cytokine levels. In normal individuals, both types of plasma showed considerably higher levels of cytokines in the samples compared to those in serum. The underlying reason for this phenomenon may be that the activation or dissolution of leukocytes, when the whole blood was introduced into anticoagulant tubes, led to cytokine release along with the release of endogenous inflammatory markers related to the anti-agglutination process of blood; this was eventually detected by immunoassay during sample handling [16]. Due to the drive of agglutination process, IL- 6 and IL-8 levels were increased significantly in clot activator-serum than in gel-serum $[17,18]$. The cytokines obtained from gel-serum stored at $-20^{\circ} \mathrm{C}$ for $24 \mathrm{~h}$ were consistently similar in level compared to that stored at room temperature for $4 \mathrm{~h}$. In patients with CTD, the same levels of cytokines were observed in the plasma compared to that in serum, except for IL-8 and IL-17F.Owing to thrombin activation, IL-8 was largely released in ordinary clot activator tube.

This result was consistent with those obtained in previous studies [19]. IL-8 and IL-17F expression in heparin anticoagulantplasma, with calcium-dependent activation processes affected, was significantly higher than in other three types of blood samples [20]. Cytokine levels in samples taken from EDTA-plasma and gel-serum, and stored respectively at $4{ }^{\circ} \mathrm{C},-20^{\circ} \mathrm{C}$, and $-80^{\circ} \mathrm{C}$ for 3 days, were significantly higher than in the baseline samples stored at $-20^{\circ} \mathrm{C}$ for $24 \mathrm{~h}$. Interestingly, compared to EDTA-plasma, there was only a small increase in IL- 6 and IL-8 levels in samples stored at $-20^{\circ} \mathrm{C}$ for $24 \mathrm{~h}$ in gel tube. The reason for this phenomenon could be that EDTA activates monocyte and cytokine release in whole blood, as indicated in a previous study [21]. Consistent with our findings, De Jongh, et al. had reported IL- 6 to be stable in serum stored at $4^{\circ} \mathrm{C}$ up to $24 \mathrm{~h}[22,23]$. This result supported the fact that gel-serum is the preferred sample for cytokine analysis of patients with CTD.

In previous studies, plasma samples were handled with caution for cytokine detection [19,24]. Mechanisms underlying the differential cytokine levels in serum compared to those in plasma remain to be explored in detail. Currently, cytokines, especially IL6, have been implicated in the pathogenesis caused by COVID-19 $[25,26]$. Therefore, it would be important for clinicians to select optimal conditions for the simultaneous detection of multiple cytokines, in order to understand the patients' conditions and guide with appropriate medication. Our data suggested that gelserum could be recommended for sampling the reference ranges of cytokine tests using the method of AimPlex flow cytometry. If cytokines in the collected serum cannot be detected timely, it would be advisable to store the sample at $-20^{\circ} \mathrm{C}$ up to $24 \mathrm{~h}$.

\section{Declarations}

Not applicable.

\section{Funding}

This work was supported by the National Youth Science Foundation [grant number 81601402].

\section{Conflicts of Interest}

The authors have declared that there is no conflict of interest.

\section{References}

1. Kany S, Vollrath JT, Relja B (2019) Cytokines in inflammatory disease. Int J Mol Sci 20(23): 6008.

2. Tisoncik JR, Korth MJ, Simmons CP, Farrar J, Martin TR, et al. (2012) Into the eye of the cytokine storm. Microbiol Mol Biol Rev 76(1): 16-32.

3. Guan Q Gao X, Wang J, Sun Y, Shekhar S (2017) Cytokines in autoimmune disease. Mediators Inflamm 2017: 5089815.

4. Lai Y, Dong C (2016) Therapeutic antibodies that target inflammatory cytokines in autoimmune diseases. Int Immunol 28(4): 181-188.

5. An LL, Mehta P, Xu L, Turman S, Reimer T, et al. (2014) Complement C5a potentiates uric acid crystal-induced IL-1 $\beta$ production. Eur J Immunol 44(12): 3669-3679.

6. Hansen IS, Hoepel W, Zaat SAJ, Baeten DLP, den Dunnen J (2017) Serum IgA immune complexes promote proinflammatory cytokine production by human macrophages, monocytes, and Kupffer cells through FcaRITLR cross-talk. J Immunol 199(12): 4124-4131.

7. Voorhees T, Chang J, Yao Y, Kaplan MH, Chang CH, et al. (2011) Dendritic cells produce inflammatory cytokines in response to bacterial products from Staphylococcus aureus-infected atopic dermatitis lesions. Cell Immunol 267(1): 17-22.

8. Zhou X, Fragala MS, McElhaney JE, Kuchel GA (2010) Conceptual and methodological issues relevant to cytokine and inflammatory marker measurements in clinical research. Curr Opin Clin Nutr Metab Care 13(5): 541-547.

9. Lee JE, Kim JW, Han BG, Shin SY (2016) Impact of whole-blood processing conditions on plasma and serum concentrations of cytokines. Biopreserv Biobank 14(1): 51-55.

10. Kang HJ, Jeon SY, Park JS, Yun JY, Kil HN, et al. (2013) Identification of clinical biomarkers for pre-analytical quality control of blood samples. Biopreserv Biobank 11(2): 94-100.

11. Joseph L, Fink LM, Hauer Jensen M (2002) Cytokines in coagulation and thrombosis: a preclinical and clinical review. Blood Coagul Fibrinolysis 13(2): 105-116

12. Strande JL, Phillips SA (2009) Thrombin increases inflammatory cytokine and angiogenic growth factor secretion in human adipose cells in vitro. J Inflamm 6: 4.

13. Page MJ, Bester J, Pretorius E (2018) The inflammatory effects of TNF- $\alpha$ and complement component 3 on coagulation. Sci Rep 8: 1812.

14. Mollnes TE, Brekke OL, Fung M, Fure H, Christiansen D, et al. (2002) Essential role of the $\mathrm{C} 5 \mathrm{a}$ receptor in $\mathrm{E}$ coli-induced oxidative burst and phagocytosis revealed by a novel lepirudin-based human whole blood model of inflammation. Blood 100(5): 1869-1877. 
15. Hennø LT, Storjord E, Christiansen D, Bergseth G, Ludviksen JK, et al. (2017) Effect of the anticoagulant, storage time and temperature of blood samples on the concentrations of 27 multiplex assayed cytokines Consequences for defining reference values in healthy humans. Cytokine 97: 86-95.

16. Skogstrand K, Ekelund CK, Thorsen P, Vogel I, Jacobsson B, et al. (2008) Effects of blood sample handling procedures on measurable inflammatory markers in plasma, serum and dried blood spot samples. ] Immunol Methods 336(1): 78-84.

17. Aziz N, Irwin MR, Dickerson SS, Butch AW (2004) Spurious tumor necrosis factoralpha and interleukin- 6 production by human monocytes from blood collected in endotoxin-contaminated vacutainer blood collection tubes. Clin Chem 50(11): 2215-2216.

18. Bester J, Matshailwe C, Pretorius E (2018) Simultaneous presence of hypercoagulation and increased clot lysis time due to IL- $1 \beta$, IL-6 and IL8. Cytokine 110: 237-242.

19. Rosenberg Hasson Y, Hansmann L, Liedtke M, Herschmann I, Maecker HT (2014) Effects of serum and plasma matrices on multiplex immunoassays. Immunol Res 58(2-3): 224-233.

20. Wu W, Booth JL, Coggeshall KM, Metcalf JP (2006) Calcium-dependent viral internalization is required for adenovirus type 7 induction of IL-8 protein. Virology 355(1): 18-29.

ISSN: 2574-1241

DOI: 10.26717/BJSTR.2021.38.006193

Jiangfeng Zhao. Biomed J Sci \& Tech Res

(c) (P) This work is licensed under Creative By Commons Attribution 4.0 License

Submission Link: https://biomedres.us/submit-manuscript.php
21. Patil R, Shukre S, Paranjape R, Thakar M (2013) Heparin and EDTA anticoagulants differentially affect the plasma cytokine levels in humans. Scand J Clin Lab Invest 73(5): 452-455.

22. De Jongh R, Vranken J, Vundelinckx G, Bosmans E, Maes M, et al. (1997) The effects of anticoagulation and processing on assays of IL-6, sIL-6R, sIL-2R and soluble transferring receptor. Cytokine 9(9): 696-701.

23. Flower L, Ahuja RH, Humphries SE, Mohamed Ali V (2000) Effect of sample handling on the stability of interleukin-6, tumor necrosis factor alpha and leptin. Cytokine 12(11): 1712-1716.

24. Aziz N, Detels R, Quint JJ, Li Q, Gjertson D, et al. (2016) Stability of cytokines, chemokines and soluble activation markers in unprocessed blood stored under different conditions. Cytokine 84: 17-24.

25. McGonagle D, Sharif K, O’Regan A, Bridgewood C (2020) The role of cytokines including interleukin-6 in COVID-19 induced pneumonia and macrophage activation syndrome-like disease. Autoimmun Rev 19(6): 102537.

26. Sarzi Puttini P, Giorgi V, Sirotti S, Marotto D, Ardizzone S, et al. (2020) COVID-19, cytokines and immunosuppression: what can we learn from severe acute respiratory syndrome? Clin Exp Rheumatol 38(2): 337-342.

$\begin{array}{ll}\text { BIOMEDICAL } & \text { Assets of Publishing with us } \\ \text { RESEARCHES } & \text { - Global archiving of articles } \\ \text { - Immediate, unrestricted online access }\end{array}$

